\begin{tabular}{|c|c|c|c|}
\hline Case Reports in & \multicolumn{2}{|c|}{ Case Rep Gastroenterol 2017;11:265-270 } & \multirow[b]{2}{*}{$\begin{array}{l}\text { Karger } \\
\text { Open access }\end{array}$} \\
\hline Gastroenterology & $\begin{array}{l}\text { DOI: 10.1159/000462967 } \\
\text { Published online: May 17, } 2017\end{array}$ & $\begin{array}{l}\text { (c) } 2017 \text { The Author(s) } \\
\text { Published by S. Karger AG, Basel } \\
\text { www.karger.com/crg }\end{array}$ & \\
\hline & $\begin{array}{l}\text { This article is licensed under } \\
\text { International License (CC BY-1 } \\
\text { Usage and distribution for comn }\end{array}$ & $\begin{array}{l}\text { nons Attribution-NonCommercia } \\
\text { ger.com/Services/OpenAccessLice } \\
\text { uires written permission. }\end{array}$ & \\
\hline
\end{tabular}

\title{
Carcinoma of the Papilla of Vater after Diversion Operation for Pancreaticobiliary Maljunction
}

\author{
Takahiro Yamanaka $^{a} \quad$ Kenichiro Araki $^{\mathrm{a}}$ Norihiro Ishii ${ }^{\mathrm{a}}$ \\ Mariko Tsukagoshi ${ }^{a}$ Takamichi Igarashi $^{a}$ Akira Watanabe $^{a}$ \\ Norio Kubo ${ }^{a}$ Hiroyuki Kuwano $^{b}$ Ken Shirabe $^{a}$ \\ ${ }^{a}$ Department of Hepatobiliary and Pancreatic Surgery, Gunma University Graduate School \\ of Medicine, Maebashi, Japan; ${ }^{b}$ Department of General Surgical Science (Surgery I), \\ Gunma University Graduate School of Medicine, Maebashi, Japan
}

\section{Keywords}

Pancreaticobiliary maljunction $\cdot$ Carcinoma $\cdot$ Papilla of Vater

\begin{abstract}
Pancreaticobiliary maljunction (PBM) is a congenital malformation that is associated with biliary cancer development. When patients are diagnosed with PBM, a diversion operation is recommended. Although a risk remains for developing residual bile duct carcinoma following diversion, the development of a carcinoma of the ampulla of Vater after a diversion operation for PBM is rare. We present a treated case of carcinoma of the ampulla of Vater after a diversion operation for PBM. A 65-year-old woman presented with abdominal pain. She had undergone extrahepatic bile duct resection and cholecystectomy 2 years 9 months previously for the treatment of type Ic PBM according to the Todani classification. At the current admission for evaluation of the abdominal pain, computed tomography and magnetic resonance imaging showed only dilation of the main pancreatic duct. However, gastrointestinal endoscopy showed a tumor at the papilla of Vater, and biopsy revealed adenocarcinoma of the papilla of Vater. We performed pylorus-preserving pancreaticoduodenectomy, and the pathological diagnosis was moderately differentiated tubular adenocarcinoma of the papilla of Vater with no metastasis to the lymph nodes. The patient remained in good health for 3 years postoperatively. Carcinoma of the papilla of Vater after a diversion operation for PBM is
\end{abstract}


Yamanaka et al.: Carcinoma of the Papilla of Vater after Diversion Operation for Pancreaticobiliary Maljunction

rare. In this case, a diagnosis could not be made by computed tomography or magnetic resonance imaging; the definitive diagnosis was obtained with gastrointestinal endoscopy. Careful postoperative follow-up with gastrointestinal endoscopy in addition to imaging examination may be needed after a diversion operation for PBM.

\section{Background}

Pancreaticobiliary maljunction (PBM) is a congenital malformation in which the pancreatic and bile ducts are anatomically joined outside the duodenal wall. In addition, the reflux of pancreatic juices into the biliary tract provokes higher rates of biliary tract cancer. So, when patients are diagnosed with PBM, a surgical treatment is recommended before the onset of biliary tract cancer [1-3]. Although a risk remains for developing residual bile duct carcinoma after a diversion operation for PBM, the development of a carcinoma of the ampulla of Vater after diversion is rare. We treated a patient with carcinoma of the ampulla of Vater after a diversion operation for PBM. Only 1 similar case has been reported in the literature [4]. We present our case with a brief review of the literature.

\section{Case Presentation}

A 65-year-old woman with abdominal pain presented to a local hospital. She had undergone extrahepatic bile duct resection, cholecystectomy, and choledochojejunostomy at our hospital 2 years 9 months previously for treatment of type Ic PBM according to the Todani classification [5]. At the local hospital, physical examination revealed epigastric pain and computed tomography (CT) showed dilation of the main pancreatic duct (Fig. 1a). The patient improved with 4 days of bed rest at the local hospital. She then presented to our hospital to determine the cause of the abdominal pain and dilation of the main pancreatic duct.

Laboratory data on admission to our hospital were as follows: white blood cell count, 6,200/ $\mu \mathrm{L}$; red blood cell count, $404 \times 10^{4} / \mu \mathrm{L}$; hemoglobin, $12.4 \mathrm{~g} / \mathrm{dL}$; hematocrit, $38.8 \%$; platelets, $28.6 \times 10^{4} / \mu \mathrm{L}$; total bilirubin, $0.3 \mathrm{mg} / \mathrm{dL}$; aspirate aminotransferase, $22 \mathrm{IU} / \mathrm{L}$; alanine aminotransferase, $20 \mathrm{IU} / \mathrm{L}$; alkaline phosphatase, $317 \mathrm{IU} / \mathrm{L} ; \gamma$-glutamyl transferase, 33 IU/L; amylase, $110 \mathrm{U} / \mathrm{L}$; blood urea nitrogen, $19 \mathrm{mg} / \mathrm{dL}$; creatinine, $0.60 \mathrm{mg} / \mathrm{dL}$; C-reactive protein, $0.04 \mathrm{mg} / \mathrm{dL}$; carcinoembryonic antigen (CEA), $3.9 \mathrm{ng} / \mathrm{mL}$, and carbohydrate antigenic determinant 19-9 (CA19-9), $15 \mathrm{U} / \mathrm{mL}$. The complete blood cell count was within the reference range, and hepatic, biliary, and pancreatic enzyme concentrations were not eleva ted. The concentrations of tumor markers, including CEA and CA19-9, were normal.

Gastrointestinal endoscopy revealed a tumor of the papilla of Vater, and adenocarcinoma of the papilla of Vater was diagnosed by biopsy (Fig. 1b). Magnetic resonance imaging (MRI) and CT revealed dilation of the main pancreatic duct. However, the tumor at the papilla of Vater was not clear on MRI. There was no obvious accumulation of fluorodeoxyglucose on whole-body fluorodeoxyglucose-positron emission tomography. There was also no distant metastasis. We then performed pylorus-preserving pancreaticoduodenectomy and pancreaticojejunostomy with a diagnosis of carcinoma of the papilla of Vater. Intraoperatively, we performed adhesiolysis of the abdominal wall, liver, and small intestine and found that the tumor at the papilla of Vater was approximately $1 \mathrm{~cm}$ in diameter. We removed the pancreatic head and duodenum and performed pancreaticojejunostomy and gastrojejunostomy. The pathological diagnosis was moderately differentiated tubular adenocarcinoma of the 
Yamanaka et al.: Carcinoma of the Papilla of Vater after Diversion Operation for Pancreaticobiliary Maljunction

papilla of Vater with no metastasis to the lymph nodes (pT2N0M0 stage IB, International Union against Cancer, UICC). The main part of the tumor was present at the common channel (Fig. 2). The specimen showed p53 expression in the cancer tissue and atypical epithelium of the retained bile duct (Fig. 3). The patient remained in good health with no recurrence for 3 years after the second operation.

\section{Discussion}

PBM is frequently associated with biliary cancer [6, 7]. Previous reports have suggested that metaplasia and dysplasia of biliary duct epithelial cells might develop at the site of bile stasis, irritation, and inflammation because pancreatic juice mixed with infected or denatured bile and pancreatic enzymes were activated by the presence of enterokinase $[2,8,9]$. Mutations in the K-ras and p53 genes have also been found in the mucosa of the bile duct in patients with PBM [10-12]. Our patient also showed high expression of p53 in the cancer tissue and atypical epithelium of the bile duct with immunostaining. In a previous report, the rate of developing biliary cancer in patients with PBM with and without choledochal dilation was 21.6 and $42.2 \%$, respectively [2]. Although cholecystectomy, resection of the extrahepatic bile duct, and hepaticojejunostomy have been recommended as standard operations for treating PBM with choledochal dilation, whether the bile duct should be removed when treating PBM without choledochal dilation remains unclear [3]. Even after undergoing a surgical procedure that stops reflux of pancreatic enzymes into the choledochus and prevents the development of biliary cancer, patients with PBM still have a risk of developing residual bile duct carcinoma [9]. The estimated incidence of cancer development after a diversion operation is $0.7 \%$, and the interval between the operation and cancer detection ranges from 1 to 19 years [9]. The development of carcinoma of the papilla of Vater after choledochojejunostomy for PBM is rare; only 1 such report has been published [4]. No reports have discussed the risk factors for carcinoma of the papilla of Vater or the relationship between PBM and carcinoma of the papilla of Vater. In the present case, the main part of the tumor was present in the common channel, which is reportedly the most frequent site of carcinoma of the papilla of Vater [7]. The residual bile duct in the pancreas was atrophic and replaced with atypical epithelium. Therefore, we considered that the PBM caused the carcinogenesis at the common channel and residual bile duct after the diversion operation for PBM. If a tumor at the common channel develops alongside the papilla of Vater, the tumor may manifest as a carcinoma of the papilla of Vater. Careful postoperative examination is important for patients who have undergone a diversion operation for PBM because jaundice is not usually observed in patients who have undergone a diversion operation of the bile duct, although it is one of the most common manifestations of carcinoma of the papilla of Vater [4]. In the present case, the patient had undergone regular follow-up CT examinations. We could not find the tumor by CT or MRI but were able to identify it by gastrointestinal endoscopy. Gastrointestinal endoscopy should be performed regularly as part of the postoperative follow-up of PBM.

\section{Conclusion}

We experienced a rare case of carcinoma of the papilla of Vater 2 years 9 months after a diversion operation for the treatment of PBM. In this case, we were able to diagnose the car- 


\section{Case Reports in Gastroenterology}

\begin{tabular}{l|l}
\hline DOI: $10.1159 / 000462967$ & (C) 2017 The Author(s). Published by S. Karger AG, Basel
\end{tabular} www.karger.com/crg

Yamanaka et al.: Carcinoma of the Papilla of Vater after Diversion Operation for Pancreaticobiliary Maljunction

cinoma not by CT or MRI but by gastrointestinal endoscopy. Careful postoperative follow-up with gastrointestinal endoscopy in addition to imaging may be necessary in such patients.

\section{Statement of Ethics}

Approval from the Ethics Committee was not required for this case report. Written informed consent was obtained from the patient for publication of this case report and any accompanying images.

\section{Disclosure Statement}

The authors declare that they received no financial support in association with this case report. The authors also declare that they have no competing interests.

\section{References}

1 Kamisawa T, Ando H, Hamada Y, Fujii H, Koshinaga T, Urushihara N, Itoi T, Shimada H; Japanese Study Group on Pancreaticobiliary Maljunction: Diagnostic criteria for pancreaticobiliary maljunction 2013. J Hepatobiliary Pancreat Sci 2014;21:159-161.

-2 Kamisawa T, Ando H, Shimada M, Hamada Y, Itoi T, Takayashiki T, Miyazaki M: Recent advances and problems in the management of pancreaticobiliary maljunction: feedback from the guidelines committee. J Hepatobiliary Pancreat Sci 2014;21:87-92.

- 3 Tashiro S, Imaizumi T, Ohkawa H, Okada A, Katoh T, Kawaharada Y, Shimada H, Takamatsu H, Miyake H, Todani T; Committee for Registration of the Japanese Study Group on Pancreaticobiliary Maljunction: Pancreaticobiliary maljunction: retrospective and nationwide survey in Japan. J Hepatobiliary Pancreat Surg 2003;10:345-351.

-4 Watanabe M, Midorikawa Y, Yamano T, Mushiake H, Fukuda N, Kirita T, Mizuguchi K, Sugiyama Y: Carcinoma of the papilla of Vater following treatment of pancreaticobiliary maljunction. World J Gastroenterol 2009;15:6126-6128.

5 Todani T, Narusue M, Watanabe Y, Tabuchi K, Okajima K: Management of congenital choledochal cyst with intrahepatic involvement. Ann Surg 1978;187:272-280.

-6 Ohashi T, Wakai T, Kubota M, Matsuda Y, Arai Y, Ohyama T, Nakaya K, Okuyama N, Sakata J, Shirai Y, Ajioka Y: Risk of subsequent biliary malignancy in patients undergoing cyst excision for congenital choledochal cysts. J Gastroenterol Hepatol 2013;28:243-247.

-7 Miyazaki M, Takada T, Miyakawa S, Tsukada K, Nagino M, Kondo S, Furuse J, Saito H, Tsuyuguchi T, Chijiiwa K, Kimura F, Yoshitomi H, Nozawa S, Yoshida M, Wada K, Amano H, Miura F; Japanese Association of Biliary Surgery; Japanese Society of Hepato-Pancreatic Surgery; Japan Society of Clinical Oncology: Risk factors for biliary tract and ampullary carcinomas and prophylactic surgery for these factors. J Hepatobiliary Pancreat Surg 2008;15:15-24.

-8 Park SW, Lee SH, Eum YO, Oh HS, Lee D, Jin E, Chung K, Hwang JH: One case of common bile duct cancer mimicking cystic neoplasm of the pancreas, arising 9 years after excision of a choledochal cyst. Clin Endosc 2012;45:435-439.

\$ Watanabe Y, Toki A, Todani T: Bile duct cancer developed after cyst excision for choledochal cyst. J Hepatobiliary Pancreat Surg 1999;6:207-212.

10 Masuhara S, Kasuya K, Aoki T, Yoshimatsu A, Tsuchida A, Koyanagi Y: Relation between K-ras codon 12 mutation and p53 protein overexpression in gallbladder cancer and biliary ductal epithelia in patients with pancreaticobiliary maljunction. J Hepatobiliary Pancreat Surg 2000;7:198-205.

11 Tsuchida A, Itoi T: Carcinogenesis and chemoprevention of biliary tract cancer in pancreaticobiliary maljunction. World J Gastrointest Oncol 2010;2:130-135.

12 Saito F, Araki K, Yokobori T, Ishii N, Tsukagoshi M, Watanabe A, Kubo N, Altan B, Shirabe K, Kuwano H: High expression of karyopherin- $\alpha 2$ and stathmin 1 is associated with proliferation potency and transformation in the bile duct and gall bladder epithelia in the cases of pancreaticobiliary maljunction. J Surg Oncol 2016;114:462-468. 
Yamanaka et al.: Carcinoma of the Papilla of Vater after Diversion Operation for Pancreaticobiliary Maljunction
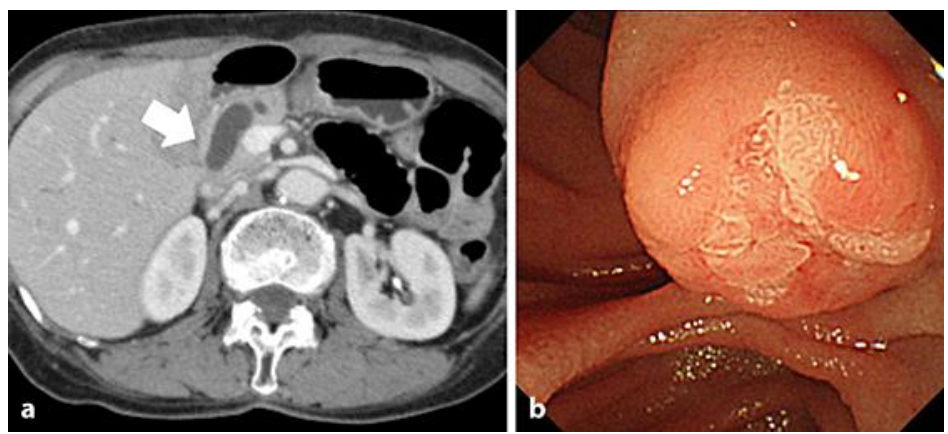

Fig. 1. a Contrast-enhanced CT showing dilation of the main pancreatic duct on the peripheral side of the papilla of Vater. The main pancreatic duct is indicated by the arrow. $\mathbf{b}$ Gastrointestinal endoscopy showing the tumor at the papilla of Vater. The pathological diagnosis according to biopsy examination was adenocarcinoma of the papilla of Vater.

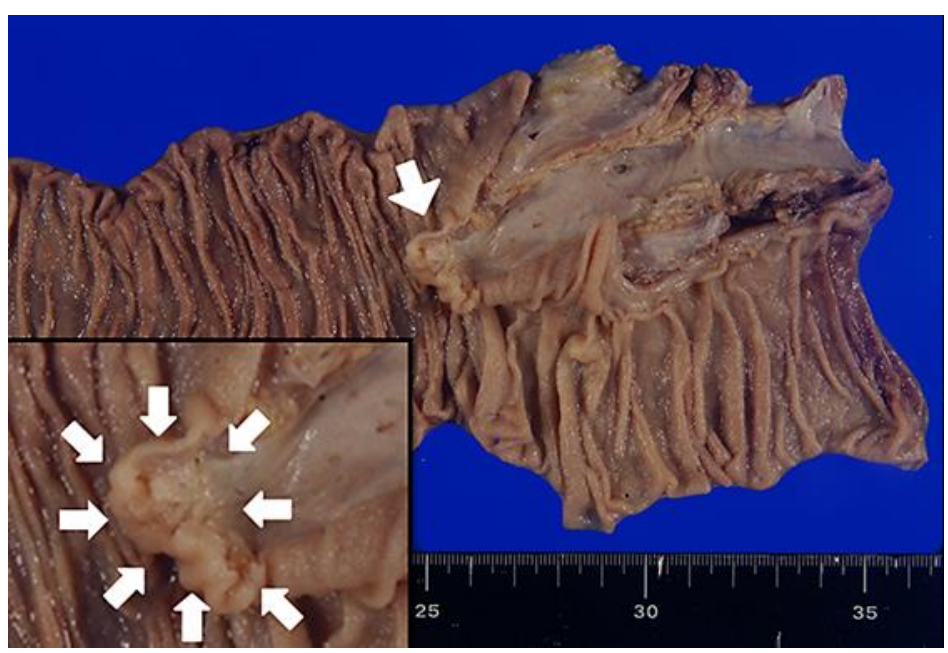

Fig. 2. Pathological findings showing a $15-\mathrm{mm}$ tumor at the papilla of Vater. The tumor is indicated by arrows. 


\section{Case Reports in Gastroenterology}
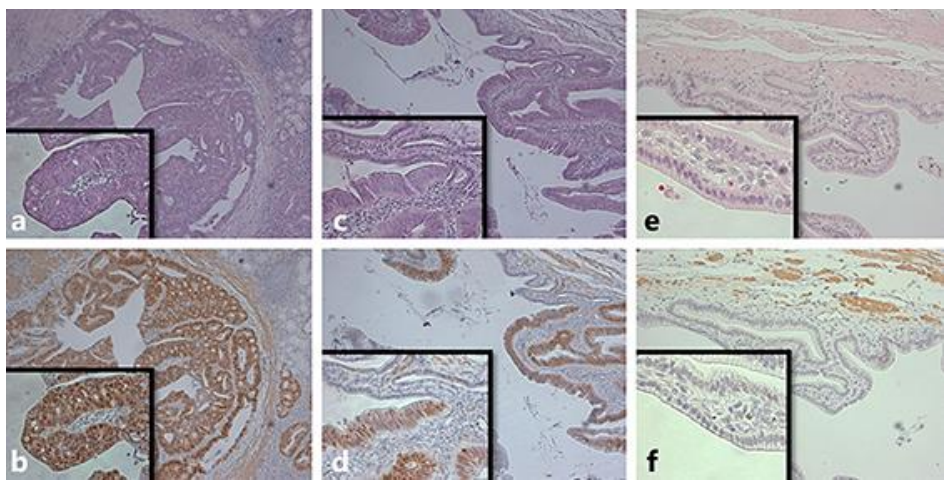

(c) 2017 The Author(s). Published by S. Karger AG, Basel www.karger.com/crg

Yamanaka et al:: Carcinoma of the Papilla of Vater after Diversion Operation for Pancreaticobiliary Maljunction

Fig. 3. a Examination of the resected specimen revealed a diagnosis of moderately differentiated tubular adenocarcinoma of the papilla of Vater. $\mathbf{b}$ The cancerous tissue showed p53 expression with immunostaining. $\mathbf{c}$ The common bile duct, which was retained in the pancreas, was atrophic and replaced by atypical epithelium $1 \mathrm{~cm}$ from the papilla of Vater and at the blind end $3 \mathrm{~cm}$ from the papilla of Vater. $\mathbf{d}$ The atypical epithelium of the retained bile duct showed p53 expression with immunostaining. e The common bile duct with normal epithelium. $f$ The normal epithelium of the bile duct did not show p53 expression with immunostaining. Magnification for all microscopy images, $\times 100, \times 200$. 